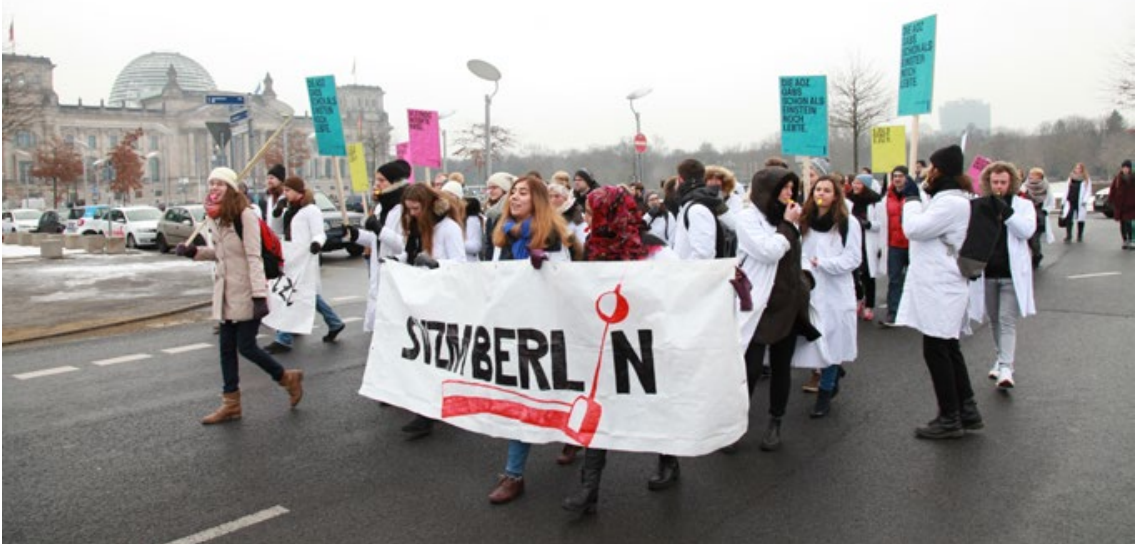

\section{Zahlen des Monats}

\section{Dick}

Im Kampf gegen zunehmende Fettleibigkeit haben sich die Techniker Krankenkasse und die Verbraucherschutzorganisation Foodwatch zusammengetan und eine Studie erstellt. Danach hält sich fast jeder Zweite in Deutschland für zu dick. 27 Prozent der Befragten leiden an Herz-Kreislauf-Problemen und 15 Prozent an Diabetes. Immerhin wird den Menschen eine ausgewogene Ernährung immer wichtiger. 45 Prozent der Befragten gaben an, Essen müsse vor allem gesund sein. Das Kriterium „lecker“ folgt mit 41 Prozent auf dem zweiten Platz.

\section{Dicker}

Ein dickes Polster hat sich die Bundeshauptstadt im vergangenen Jahr zugelegt. In Berlin konnte überraschend der stolze Überschuss von 1,25 Milliarden Euro erzielt werden. Damit nahm das Land Berlin deutlich mehr ein als vor Monaten prognostiziert. Nach der Steuerschätzung im November war der Senat noch von einem Plus von 500 Millionen Euro ausgegangen. Grund für den Überschuss seien vor allem deutlich gestiegene Einnahmen bei der Gewerbesteuer, der Körperschaftssteuer und der veranlagten Einkommensteuer. Von wegen „Berlin ist arm, aber sexy“...

\section{Zu dick}

Mit einem dicken Plus muss auch die Bundesanwaltschaft leben. Das ist allerdings weit weniger erfreulich. Die Bundesanwälte kommen nämlich angesichts der weiter wachsenden Menge an Terrorverfahren offenbar an ihre Belastbarkeitsgrenzen. Die Terrorismus-Abteilung der Bundesanwaltschaft hatte 2016 rund 240 Verfahren eingeleitet. Bei etwa 200 geht es um den Verdacht islamistisch motivierten Terrors. Der Konflikt in Syrien und im Irak bildet den Schwerpunkt. Der Generalbundesanwalt nannte 140 Verfahren gegen rund 200 Beschuldigte. Anfang 2014 seien es noch fünf Verfahren mit acht Beschuldigten gewesen.
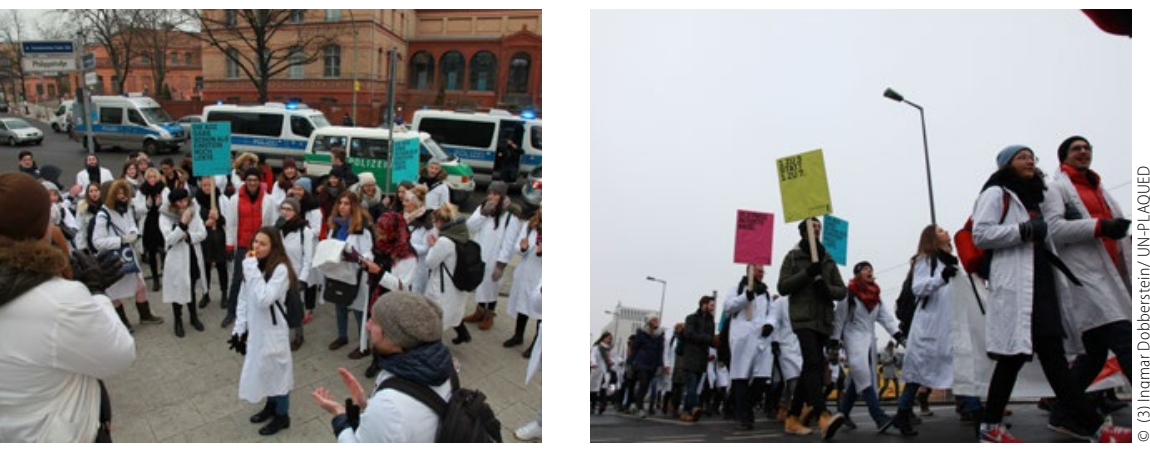

Bundesweiter Tag der zahnärztlichen Berufsausbildung

\title{
Berliner Studenten demonstrieren für neue $\mathrm{AOZ}$
}

Mehr als 60 Jahre ist sie alt. Also gut dreimal so viel wie diejenigen, die sie betrifft. Damit eine lang ersehnte Reform der Approbationsordnung für Zahnärzte (AOZ) noch in dieser Legislaturperiode wahr wird, hat die Studentenschaft im Januar einen bundesweiten Tag der zahnärztlichen Berufsausbildung ausgerufen. In
Berlin gingen rund 80 Zahnmedizinstudierende der Charité auf die Straße. Mit der Forderung „Neue AOZ - jetzt!“ zogen sie durch das Regierungsviertel und demonstrierten gegen weitere Verzögerung bei der Umsetzung der neuen AOZ.

Mehr zum Thema ab Seite 16.

$m f$

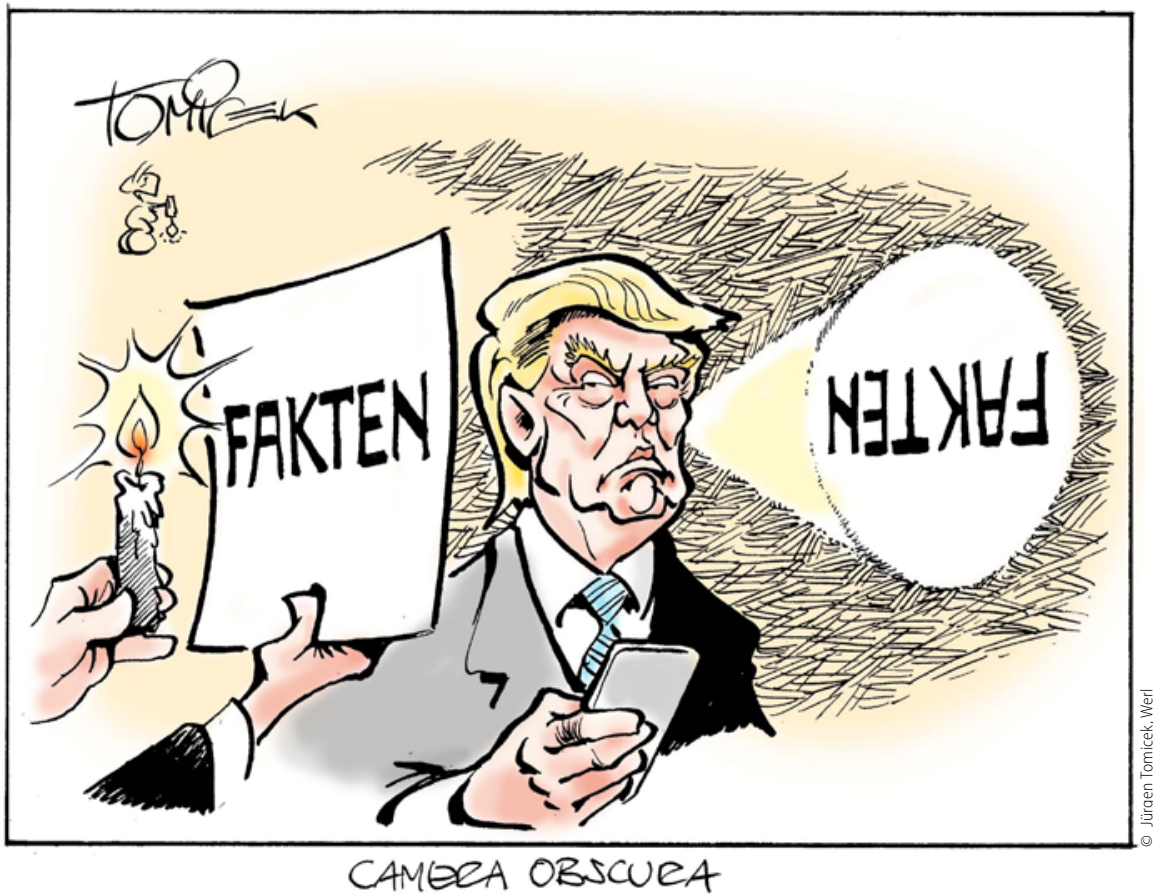

